\title{
Audit of tumour histopathology reviewed by a regional oncology centre
}

\author{
R J Prescott, S Wells, D L Bisset, S S Banerjee, M Harris
}

\begin{abstract}
Aims-To analyse the diagnostic differences in reporting tumour histopathology between a district general hospital and a regional oncology centre.

Methods-Tumour histopathology reports $(n=227)$ extracted from Bolton General Hospital files between 1988 and 1992 were compared with the corresponding Christie Hospital (oncology centre) reports, the same material having been seen at both hospitals.

Results-Diagnostic agreement existed in $\mathbf{7 7 \%}$ of all cases. The incidence of major discrepancies was $\mathbf{8} \cdot \mathbf{3 7} \%$. Of the diagnoses, $19(36 \%)$ cases involved major discrepancies and 34 (64\%) cases minor discrepancies. Most discrepancies occurred in the lymphoma group and involved subclassification of Hodgkin's and non-Hodgkin's lymphoma. Ki1 anaplastic large cell lymphoma and $T$ cell rich $B$ cell lymphoma were problematic diagnoses. The correct grading of follicle centre cell lymphomas using the Kiel classification was another problem area. In 19 cases certain aspects of immunohistochemistry produced discrepancies. In one case an incorrect diagnosis was made at the oncology centre and in another both centres gave an incorrect diagnosis.
\end{abstract}

Conclusions-Areas of diagnostic difficulty mainly involve the subclassification of lymphomas. Review of tumour pathology by experts is recommended, at least in certain categories, to ensure correct diagnosis and uniformity in subclassification of tumours.

(f Clin Pathol 1995,48:245-249)

Keywords: Audit, tumour, histopathology.

Department of Histopathology, Bolton General Hospital, Bolton

R J Prescott

$S$ Wells

D L Bisset

Department of

Histopathology,

Christie Hospital,

Manchester

S S Banerjee

M Harris

Correspondence to:

Dr R J Prescott, Department

of Histopathology,

Blackburn Royal Infirmarn BB2 3LR.

Accepted for publication

8 August 1994

Quality assessment in histopathology is now commonplace and takes the form of internal and external quality control systems. ${ }^{12}$ Review of histopathological cases by specialist panels, either for opinions or confirmation of diagnoses before further investigation or treatment at specialist centres, has been taking place for many years.

Bolton General Hospital is a district general hospital which refers selected patients with malignant neoplastic conditions to a regional cancer treatment centre, the Christie Hospital, for specialist surgery, radiotherapy and chemotherapy. It is customary practice for selected histological diagnoses reached at Bolton General Hospital to be reviewed at Christie Hospital by their pathologists, who have a specialist interest in neoplastic conditions and receive material from the whole of the North West region. Histological reports made at Bolton General Hospital are sent with unstained sections or blocks, or both, to the Christie Hospital pathology department where, following assessment, a copy of their pathological findings is sent back to Bolton General Hospital.

By comparing the diagnoses, an evaluation of the number and types of discrepancies was made. To the best of our knowledge, this type of study has not been performed before and it investigates the role of specialist pathologists as well as some of the difficult diagnostic problems in tumour pathology.

\section{Methods}

By examining the record files at Bolton General Hospital, we were able to extract 227 reports of diagnoses reached at Bolton General Hospital and reviewed at Christie Hospital, spanning a five year period from 1988 to 1992 . All of the reports contained confident diagnoses made at Bolton General Hospital and referred cases seeking a second opinion were excluded. Each dual report was examined and any diagnostic discrepancies were recorded and divided into major and minor differences. Major discrepancies were defined as those errors which could lead to serious erroneous clinical management and treatment (for example, benign neoplasms misdiagnosed as malignant or vice versa, incorrect histogenetic tumour category such as sarcoma misdiagnosed as carcinoma or vice versa, and grade of non-Hodgkin's lymphoma). Minor discrepancies were defined as those which would not lead to serious erroneous clinical management and treatment, and mostly involved differences in tumour subclassification.

\section{Results}

Diagnostic agreement was reached in $77 \%$ of cases and some degree of disagreement was found in $23 \%$. An analysis of the anatomical sites at which these differences occurred is given in table 1. Lymphomas constituted the largest diagnostic group referred to Christie Hospital (42\% of total) and of the 95 cases of lymphoma, $23 \%$ showed diagnostic disagreement. Of all discrepant diagnoses, 36\% (19 cases) were regarded as major discrepancies and $64 \%$ (34 cases) were regarded as minor discrepancies. Further analysis is best achieved by looking at the anatomical groups separately. 
LYMPHORETICULAR BIOPSIES

None of the cases diagnosed at Bolton General Hospital as malignant lymphomas were considered to be reactive or benign entities at Christie Hospital. Table 2 shows all of the lymph node diagnoses where there was disagreement; 11 cases constituted major discrepancies and 11 others constituted minor discrepancies.

The major discrepancies noted were as follows: (a) misdiagnosis of Kil anaplastic large cell lymphoma ( $\mathrm{Ki} 1 \mathrm{ACL}$ ) (cases 1 to 3 ) as metastatic carcinoma or Hodgkin's disease; (b) incorrect classification of non-Hodgkin's lymphoma (case 7); (c) incorrect grading of follicle centre cell lymphoma (cases 8 to 10 and 16); (d) misdiagnosis of $\mathrm{T}$ cell rich $\mathrm{B}$ cell lymphoma (cases 13 and 14) as Hodgkin's disease; and (e) misdiagnosis of Hodgkin's disease (case 18) as probable non-Hodgkin's lymphoma.

The minor discrepancies noted were as follows: (a) misdiagnosis of Kil ACL (cases 4 and 5); (b) misdiagnosis of follicle centre cell (FCC) lymphomas (case 6); (c) misdiagnosis of centrocytic lymphomas (cases 11 and 12); (d) misdiagnosis of $\mathrm{T}$ cell rich $\mathrm{B}$ cell lymphoma (case 15); (e) misdiagnosis of Hodgkin's disease subclassification (case 17); and (f) misdiagnosis of specific differentiation features in metastatic tumours (cases 19 to 22 ).

In the 30 cases of FCC lymphomas diagnosed at both centres the use of the terms diffuse, follicular and diffuse and follicular were at variance in eight cases.

\section{TESTICULAR NEOPLASMS}

Six minor and no major discrepancies were found (table 3). The differences could be grouped as follows: (a) missed features: focal yolk sac differentiation and intratubular germ cell neoplasia (cases 1,2 and 4); (b) subclassification of germ cell tumours into differentiated, intermediate and undifferentiated teratoma (cases 4 to 6 ); and (c) identification of anaplastic seminoma (case 3 ).

\section{SOFT TISSUE NEOPLASMS}

One major and four minor discrepancies were found (table 4). Case 1 represents a major

Table 1 Anatomical sites where discrepant diagnoses were reached

\begin{tabular}{|c|c|c|c|c|}
\hline \multirow[b]{2}{*}{ Site } & \multirow[b]{2}{*}{ Number } & \multirow[b]{2}{*}{ Disagreed diagnosis } & \multicolumn{2}{|c|}{ Discrepancies } \\
\hline & & & Major & Minor \\
\hline Lymph node & 95 & 22 & 11 & 11 \\
\hline Testis & 21 & 6 & 0 & 6 \\
\hline Soft tissue & 17 & 5 & 1 & 4 \\
\hline Gynaecological sites & 22 & 5 & 2 & 3 \\
\hline Skin & 16 & 4 & 2 & 2 \\
\hline Gastrointestinal tract & 13 & 3 & 1 & 2 \\
\hline Respiratory tract & 14 & 2 & 1 & 1 \\
\hline Urinary tract & 9 & 2 & 0 & 2 \\
\hline Thyroid & 4 & 1 & 0 & 1 \\
\hline Breast & 5 & 2 & 0 & 2 \\
\hline Liver & 3 & 0 & 0 & 0 \\
\hline Bone & 2 & 0 & 0 & 0 \\
\hline Tongue & 2 & 1 & 1 & 0 \\
\hline Conjunctiva & 1 & 0 & 0 & 0 \\
\hline Retroperitoneum & 1 & 0 & 0 & 0 \\
\hline Ear external meatus & 1 & 0 & 0 & 0 \\
\hline Parotid & 1 & 0 & 0 & 0 \\
\hline Total & 227 & 53 & 19 & 34 \\
\hline
\end{tabular}

Table 2 Lymphoreticular biopsy disagreements

\begin{tabular}{|c|c|c|}
\hline \multirow[b]{2}{*}{ Case No. } & \multicolumn{2}{|l|}{ Diagnosis } \\
\hline & Bolton General Hospital & Christie Hospital \\
\hline 1 & \multirow{11}{*}{$\begin{array}{l}\text { Metastatic carcinoma } \\
\text { Metastatic carcinoma } \\
\text { Lymphocyte depleted Hodgkin's lymphoma } \\
\text { High grade non-Hodgkin's lymphoma } \\
\text { Pleomorphic T cell lymphoma } \\
\text { Well differentiated lymphocytic lymphoma } \\
\text { Lymphoblastic lymphoma } \\
\text { Centroblastic lymphoma, diffuse } \\
\text { Centroblastic lymphoma } \\
\text { Centroblastic/centrocytic lymphoma } \\
\text { Lymphocytic non-Hodgkin's lymphoma/chro } \\
\text { lymphocytic leukaemia }\end{array}$} & Kil ACL \\
\hline 2 & & Kil ACL \\
\hline 3 & & Kil ACL \\
\hline 4 & & Kil ACL \\
\hline 5 & & Kil ACL \\
\hline 6 & & Centroblastic/centrocytic lymphoma, follicular and diffuse \\
\hline 7 & & Centroblastic lymphoma, diffuse \\
\hline 8 & & Centroblastic/centrocytic lymphoma, follicular and diffuse \\
\hline 9 & & Centroblastic/centrocytic lymphoma, follicular and diffuse \\
\hline 10 & & Centroblastic lymphoma, diffuse \\
\hline 11 & & Centrocytic lymphoma, diffuse \\
\hline 12 & $\begin{array}{l}\text { Lymphocytic non-Hodgkin's lymphoma/chronic } \\
\text { lymphocytic leukaemia }\end{array}$ & Centrocytic lymphoma, diffuse \\
\hline 13 & \multirow{6}{*}{$\begin{array}{l}\text { Nodular sclerosing Hodgkin's lymphoma } \\
\text { ? Hodgkin's lymphoma } \\
\text { T cell lymphoma with epithelioid histiocyte, high grade } \\
\text { Centroblastic/centrocytic lymphoma } \\
\text { Mixed cellularity Hodgkin's lymphoma } \\
\text { Unclassified malignant neoplasm, probably non- } \\
\text { Hodgkin's lymphoma }\end{array}$} & T cell rich B cell lymphoma \\
\hline 14 & & $\mathrm{~T}$ cell rich $\mathrm{B}$ cell lymphoma \\
\hline 15 & & T cell rich B cell lymphoma \\
\hline 16 & & Large cell (B cell) lymphoma (unclassified, high grade) \\
\hline 17 & & Lymphocyte predominant Hodgkin's lymphoma \\
\hline 18 & & Lymphocyte depleted Hodgkin's lymphoma \\
\hline 19 & Metastatic undifferentiated carcinoma & Metastatic poorly differentiated squamous carcinoma \\
\hline 20 & Metastatic undifferentiated carcinoma & Metastatic poorly differentiated adenocarcinoma \\
\hline 21 & Metastatic squamous carcinoma & Mucoepidermoid carcinoma \\
\hline 22 & Metastatic carcinoma with HCG positive giant cells & Metastatic large cell carcinoma with giant cells (HCG \\
\hline & (? testicular primary) & negative) \\
\hline
\end{tabular}


Table 3 Testicular biopsy diagreements

\begin{tabular}{lll}
\hline & Diagnosis & \\
\cline { 2 - 3 } Case No. & Bolton General Hospital & Christie Hospital \\
\hline 1 & $\begin{array}{l}\text { Malignant teratoma undifferentiated plus seminoma } \\
\text { Teratoma differentiated }\end{array}$ & $\begin{array}{l}\text { Malignant teratoma undifferentiated plus yolk sac tumour } \\
\text { Teratoma differentiated plus focal in situ germ cell } \\
\text { neoplasia }\end{array}$ \\
3 & $\begin{array}{l}\text { Anaplastic seminoma } \\
\text { Malignant teratoma intermediate plus focal yolk sac } \\
\text { tumour }\end{array}$ & $\begin{array}{l}\text { Malignant teratoma, intermediate } \\
\text { Malignant teratoma differentiated plus seminoma }\end{array}$ \\
\hline
\end{tabular}

Table 4 Soft tissue biopsy disagreements

\begin{tabular}{lll}
\hline & Diagnosis & \\
\cline { 2 - 3 } Case No. & Bolton General Hospital & Christie Hospital \\
\hline 1 & Sarcoma not specified & Metastatic melanoma \\
2 & Malignant fibrous histocytoma & Leiomyosarcoma \\
3 & Malignant nerve sheath tumour & Leiomyosarcoma \\
4 & Sarcoma not specified & Leiomyosarcoma \\
5 & ? Malignant nerve sheath & Biphasic synovial sarcoma \\
\hline
\end{tabular}

Table 5 Gynaecological biopsy disagreements

\begin{tabular}{lll}
\hline & Diagnosis & \\
\cline { 2 - 3 } Case No. & Bolton General Hospital & Christie Hospital \\
\hline 1 & Condylomatous CIN II plus III & Condylomatous CIN I \\
2 & Cervical carcinosarcoma & Poorly differentiated adenocarcinoma \\
3 & Uterine mixed Mullerian tumour with malignant cartilage & Adenosquamous carcinoma \\
4 & Ovarian serous tumour of borderline malignancy & Papillary serous cystadenocarcinoma \\
5 & Ovarian non-Hodgkin's lymphoma, centroblastic/centrocytic & Non-Hodgkin's lymphoma, centroblastic, diffuse \\
\hline
\end{tabular}

discrepancy and can be attributed to conflicting immunohistochemical results. At Bolton General Hospital the spindle cell neoplasm was vimentin positive and Cam $5 \cdot 2$ and $\mathrm{S}-100$ protein negative, whereas at Christie Hospital the tumour was vimentin, $\mathrm{S}-100$ protein, HMB45, and NKIC 3 positive and Cam $5 \cdot 2, \mathrm{CK} 1$, desmin, and LCA (leucocyte common antigen) negative, indicating a diagnosis of malignant melanoma.

In cases 2, 3 and 4 appropriate immunohistochemistry with a wide range of markers, including three muscle markers, enabled the diagnosis of leiomyosarcoma to be reached at Christie Hospital. At Bolton General Hos- pital immmunohistochemistry was either not performed or involved a limited number of markers.

\section{GYNAECOLOGICAL NEOPLASMS}

Two major and three minor discrepancies were found (table 5). The major discrepancies were as follows: (a) incorrect grading of cervical intraepithelial neoplasia (case 1). A third pathologist $(R P)$ reviewed this biopsy specimen and unequivocally agreed with the Bolton General Hospital diagnosis; and (b) incorrect grading of a follicle centre cell lymphoma (case 5).

Table 6 Diagnostic disagreements other sites

\begin{tabular}{|c|c|c|}
\hline \multirow[b]{2}{*}{ Case No. } & \multicolumn{2}{|l|}{ Diagnosis } \\
\hline & Bolton General Hospital & Christie Hospital \\
\hline $\begin{array}{l}\text { Skin } \\
1^{*} \\
2 \\
3 \\
4\end{array}$ & $\begin{array}{l}\text { ? Malignant melanoma } \\
\text { ? malignant epithelioid Schwannoma } \\
\text { Lentigo maligna and invasive malignant melanoma } \\
\text { Malignant melanoma } \\
\text { Large cell non-Hodgkin's lymphoma (high grade) }\end{array}$ & $\begin{array}{l}\text { Metastatic carcinoma } \\
\text { ? primary adnexal tumour } \\
\text { Lentigo maligna and superficial spreading melanoma plus invasion } \\
\text { "Spitzoid" malignant melanoma } \\
\text { Centroblastic/centrocytic, diffuse non-Hodgkin's lymphoma }\end{array}$ \\
\hline $\begin{array}{ll}\text { Gastrointestinal tract } \\
5 & \text { rectum } \\
6 & \text { stomach } \\
7 & \text { ileocaecal mass } \\
8 & \text { bronchus } \\
9 & \text { Nose (middle turbinate) }\end{array}$ & $\begin{array}{l}\text { Liposarcoma } \\
\text { Malignant Schwannoma } \\
\text { ? T cell lymphoma/leukaemic infiltrate } \\
\text { Poorly differentiated carcinoma } \\
\text { MALToma }\end{array}$ & $\begin{array}{l}\text { Unclassifiable malignant tumour } \\
\text { Leiomyosarcoma } \\
\text { Acute myeloid leukaemia/acute myelomonocytic leukaemia } \\
\text { Malignant melanoma } \\
\text { Non-Hodgkin's lymphoma, centroblastic/centrocytic, follicular and } \\
\text { diffuse }\end{array}$ \\
\hline $\begin{array}{l}\text { Urinary tract } \\
10 \text { bladder } \\
11 \text { kidney }\end{array}$ & $\begin{array}{l}\text { In situ transitional cell carcinoma with focal stromal invasion } \\
\text { Sarcoma }\end{array}$ & $\begin{array}{l}\text { Flat in situ transitional cell carcinoma. No stromal invasion } \\
\text { Unclassified malignant spindle cell tumour }\end{array}$ \\
\hline $\begin{array}{l}\text { Thyroid } \\
12\end{array}$ & Anaplastic carcinoma (cytokeratin negative) & Anaplastic carcinoma (cytokeratin positive) \\
\hline $\begin{array}{l}\text { Tongue } \\
13\end{array}$ & Non-Hodgkin's lymphoma, centroblastic/centrocytic & Non-Hodgkin's lymphoma, centroblastic, diffuse \\
\hline
\end{tabular}

MALT, mucosa associated lymphoid tumour. 
In cases 2 and 3 the sarcomatous elements diagnosed at Bolton General Hospital were thought to represent carcinoma with pseudosarcomatous features at Christie Hospital. Immunohistochemistry carried out at Christie Hospital showed these regions to be cytokeratin positive, substantiating their view. No immunohistochemistry had been performed at Bolton General Hospital.

\section{SKIN}

Two major and two minor discrepancies were found (table 6). A major discrepancy was noted in case 1-the diagnoses were incorrect at both centres! A recurring undifferentiated malignant neoplasm on the scalp of a middle-aged man was thought to be either metastatic malignant melanoma or malignant epithelioid Schwannoma at Bolton General Hospital because the tumour showed focal S-100 positive staining. The pathologists at Christie Hospital felt this was a metastatic carcinoma or primary adnexal carcinoma despite negative epithelial marker staining. A later recurrence was seen at a third hospital where the pathologists were able to discern vasoformative structures and thereby arrived at the correct diagnosis of epithelioid angiosarcoma. All of the recurrences stained with the vascular markers factor VIII Rag, JC70, and Q BEND 10, which had not been performed at either Christie or Bolton General Hospital.

The second major discrepancy involved incorrect grading of a follicle centre cell lymphoma (case 4). The two minor discrepancies involved subclassification of malignant melanomas.

\section{OTHER SITES}

Three major discrepancies and six minor discrepancies were found (table 6). The major discrepancies included (a) misdiagnosis of malignant melanoma based on conflicting immunohistochemical results between the two centres. At Bolton General Hospital this poorly differentiated bronchial neoplasm showed Cam $5 \cdot 2$ positive and $\mathrm{S}-100$ negative staining, whereas at Christie Hospital the tumour showed S-100 positive and Cam 5.2, EMA (epithelial membrane antigen) negative staining (case 8); (b) incorrect grading of follicle centre cell lymphoma (case 13); (c) misdiagnosis of acute myeloid leukaemia (case 7). The leukaemic infiltrate was chloroacetate esterase positive; this stain was not carried out at Bolton General Hospital.

The minor discrepancies were varied. In case 5 further biopsy specimens at Christie Hospital showed features of malignant teratoma. The cells on which a diagnosis of liposarcoma was made at Bolton General Hospital were most probably cells with degenerative vacuoles rather than true lipoblasts.

Case 10 represents a difference in the interpretation of stromal invasion in bladder transitional cell carcinomas. Case 12 represents an immunohistochemical discrepancy.

\section{Discussion}

One purpose of this audit was to categorise the types of errors and areas of diagnostic difficulty experienced in tumour pathology by pathologists at a district general hospital. By highlighting these problem areas, efforts to increase diagnostic knowledge can be made. At the same time, this audit sheds light on the necessity and role of specialist referral centres, particularly in the cost-conscious, competitive market that we, as pathologists, are having to embrace.

It is notable that in none of the 53 instances of diagnostic disagreement was a benign/reactive condition called malignant or vice versa. Most errors occurred in tumour subclassification.

In the lymphoid group the problem of diagnosing Kil ACL was apparent. This lymphoma can closely mimic metastatic carcinoma and Hodgkin's disease in haematoxylin and eosin preparations. The cells can also show EMA positive staining as well as a variety of staining patterns with $\mathrm{T}$ cell and $\mathrm{B}$ cell lymphocyte markers, ${ }^{3}$ including LCA negative staining in a proportion of cases. It is important to be aware of this entity when dealing with malignant large cell infiltrates and to include the Ber $\mathrm{H} 2$ marker in an investigative immunohistochemical panel.

$\mathrm{T}$ cell rich $\mathrm{B}$ cell lymphoma is a rare condition which, in this study, was misdiagnosed as Hodgkin's disease or $T$ cell lymphoma. Numerous reactive small $T$ lymphocytes are seen together with fewer neoplastic monoclonal blast cells of B cell lineage. A recent study of 26 cases showed the most common misdiagnosis was Hodgkin's disease. ${ }^{4}$

Inconsistencies in the diagnosis of nonHodgkin's and Hodgkin's lymphomas similar to those encountered in this study have been documented previously. ${ }^{5}$ Coppleston $e t a l^{6}$ recommended a concensus diagnosis by a team of pathologists. The distinction between low and high grade FCC lymphomas is therapeutically important and the misinterpretation of the proportions and cell types suggests problems in distinguishing centrocytes from centroblasts.

Inconsistencies in the application of the terms diffuse, follicular and diffuse and follicular to centroblastic/centrocytic lymphomas would, in practical terms, have no effect on the treatment of these lymphomas, all of which are low grade according to the Kiel classification. In the Working Formulation classification, however, these terms would have a bearing on the grade assigned.

Most of the discrepancies in the soft tissue group involved subclassification of sarcomas. There is evidence that in order to maintain a high level of diagnostic expertise in these lesions, frequent exposure to cases in necessary. ${ }^{7}$ In the North West region the incidence of soft tissue sarcoma is 18 per $10^{6}$ person years, ${ }^{8}$ which means there are approximately 70 new cases per year. This would be equivalent to four cases per annum per department or one to two cases per histopathologist if all cases were equally divided amongst all of the departments in the region. At Bolton General Hospital the pathologists saw an average of $3 \cdot 4$ 
cases per year. Studies have disclosed significant discrepancies between the initial diagnosis of sarcoma and the subsequent opinion of an expert or panel $^{79}$ and in one study where the cases reviewed had been selected for treatment $5-7 \%$ of sarcoma diagnoses were revised to non-sarcoma. ${ }^{9}$

The grading of cervical intraepithelial neoplasia (CIN) can be problematic with much intra- and interobserver variability. ${ }^{10}$ In case 1 (table 5) the interpretative error, made at Christie Hospital where far less cervical pathology is examined than at an average district general hospital, would have led to undertreatment.

It is possible that further tissue levels revealed certain additional features found by the Christie Hospital pathologists-for example, glandular differentiation in metastatic carcinomas in lymph nodes, yolk sac differentiation in testicular teratoma and stromal invasion in a bladder biopsy showing in situ transitional cell carcinoma.

There were 19 cases involving errors in immunohistochemical diagnosis. In eight cases there was disagreement in the staining reaction of a particular antibody and in two cases this led to major diagnostic discrepancies. Three cases involved misinterpretation of the results of an immunohistochemical panel and in eight cases failure to include the relevant marker led to misdiagnosis. Failure to perform staining with vascular markers in case 1 (table 6) at both centres led to several misdiagnoses of an epithelioid angiosarcoma. Furthermore, the idiosyncratic staining of this tumour with $S$ 100 protein led to the false label of malignant melanoma. Possible explanations for the differing S-100 staining in case 1 (table 6) and case 8 (table 6 ) include differing laboratory techniques, non-functioning reagents, misinterpretation of positive staining for background or non-specific staining, and possibly mislabelling of slides. The importance of quality assessment in performance and interpretation of immunological stains cannot be overstated.

Some of these cases illustrate the inadvisability of using a limited range of immunological markers, but most district general hospital laboratories have to restrict their markers to those in common use for financial reasons.

This study has some limitations. None of the cases, except two, were reviewed by a third histopathologist or panel. This raises the possibility that some of the diagnoses reached at Christie Hospital or Bolton General Hospital, or both, could be wrong. There are two cases where further follow up at another centre led to completely different diagnoses. Despite this, it is unlikely that a significant number of diagnoses reached at Christie Hospital were wrong; there has been no further clinical or pathological feedback on any of the cases to suggest this.

This study examined only one district hospital in the North West region. The results, though interesting, are limited and should not be regarded as generalisations for other institutions which may have greater or lesser diagnostic discrepancy levels.

Our findings show the value of having specialist referral centres which, through amassing large numbers of cases from the regional hospitals and referrals from afar, can offer a level of expertise not easily attained in peripheral hospitals. Lymphomas and soft tissue sarcomas can pose major diagnostic difficulties to the average pathologist and the exact classification of these tumours is important, not only in terms of correct treatment for the patient but also for epidemiological and therapeutic trial purposes. Uniformity in classification is best achieved by review of cases by pathologists with special experience. This does not mean, however, that district general hospital pathologists should opt out of making an initial diagnosis.

In view of the recent publicity about the accuracy of pathological reports, we feel that review of tumour pathology before the administration of potentially harmful radiotherapy or chemotherapy is to be encouraged and this paper suggests that this is particularly useful in certain specialised fields such as lymphoid neoplasia.

1 Murthy MSN, Derman H. Quality assurance in surgical pathology-personal and peer assessment. Am $\mathcal{f}$ Clin Pathol 1980;75:462-6.

2 Penner DW. Quality control and quality evaluation in histopathology and cytology. Pathol Annu 1973;8:1-19.

3 Stein $H$, Mason DY, Gerdes J. The expression of the Hodgkin's disease associated antigen $\mathrm{Kil}$ in reactive and neoplastic lymphoid tissue: evidence that Reed-Sternberg cells and histiocytic malignancies are derived from activated lymphoid cells. Blood 1985;66:848-58.

4 Roberts ISD, Bishop PW, Harris M, Banerjee SS. T-cell rich B-cell lymphoma: a clinicopathological study [abstract]. $\mathcal{F}$ Pathol 1993; 169 (Suppl 120):A352.

5 Inversen $\mathrm{OH}$, Sandnes K. The reliability of pathologists. A study of some cases of lymph node biopsies showing giant follicular hyperplasia or lymphoma. Acta Pathol Microbio Immunol Scand 1971;79:330-4.

6 Coppleston LW, Factor RM, Strumm B, Graff PW, Rappaport $\mathrm{H}$. Observer disagreement in the classification and histology of Hodgkin's disease. 7 Natl Cancer Inst 1970; 45:731-40.

7 Harris M, Hartley AL, Blair V, Birch JM, Banerjee SS, Freemont AJ, et al. Sarcomas in North West England: I. Histopathological peer review. Br $\mathcal{F}$ Cancer 1991;64: 315-20.

8 Hartley AL, Blair V, Harris M, Birch JM, Banerjee SS, Freemont AJ, et al. Sarcomas in North West England: II. Incidence. Br $\mathcal{F}$ Cancer 1991;64:1145-50.

9 Presant CA, Russell WO, Alexander RW, Fu YS. Soft tissue and bone sarcoma histopathology peer review: the frequency of disagreement in diagnosis and the need for second pathology opinions. The South Eastern Cance Study Group Experience. $f$ Clin Oncol 1986;4:1658-61.

10 Ismail SM, Colclough AB, Dinnen JS, Eakin D, Evans DM, Gradwell E, et al. Observer variation in histopathological diagnosis and grading of cervical intraepithelial neoplasia. diagnosis and grading of 